\title{
Teologi Kontekstual Pengunaan Darah Dalam Upacara adat Suku Dayak Ngaju Kalimantan Tengah
}

\author{
Ceria, ${ }^{1 *}$, Fransiskus Irwan Widjaja ${ }^{2}$, Otieli Harefa ${ }^{3}$, Hosea Pasaribu $^{4}$ \\ 1,2, 3,4 Prodi Teologi, STT Real Batam \\ ceria2988@gmail.com
}

\begin{abstract}
Christianity and the culture of the Ngaju Dayak tribe from the outset caused opposition. This is due to the difficulty of separating religion and customs from the Dayak Ngaju tribe who are bound by traditional rules that have been inherited by ancestors from generation to generation. Some groups consider this cultural practice to be a mistake and a sin against Christianity. But some others think if it can be accepted in the Christian faith. This research found a contextual theology that made it possible for the servants of God to be a way to see the context of Christian theology in the use of blood in traditional Ngaju Dayak ceremonies. And find the meaning behind the process of using blood that refers to Christian values.
\end{abstract}

Keywords: Contextual Theology, Blood, Traditional ceremony, Dayak Ngaju

\begin{abstract}
Abstrak
Kekristenan dan budaya suku Dayak Ngaju sejak awal menimbulkan pertentangan. Hal ini disebabkan karna sulitnya memisahkan antara agama dan adat istiadat dari suku Dayak Ngaju yang terikat dengan aturan adat yang telah diwarisi oleh nenek moyang secara turun temurun. Berapa kelompok menganggap praktik budaya tersebut sebagai sutu kesalahan dan dosa terhadap ajaran Kristen. Namun Sebagian lagi beranggapan jika hal tersebut bisa diterima dalam iman Kristen. Penelitian ini menemukan teologi kontekstual yang memungkinkan bagi para hamba Tuhan untuk menjadi jalan untuk melihat konteks teologi Kristen dalam penggunaan darah dalam upacara adat Dayak Ngaju, dan menemukan makna di balik proses penggunaan darah yang mengacu pada nilai-nilai kekristenan.

Kata kunci: Teologi Kontekstual, Darah, Upacara adat, Dayak Ngaju
\end{abstract}




\section{PENDAHULUAN}

Hampir di setiap suku bangsa di dunia mempercayai jika darah merupakan persembahan untuk menentramkan kemarahan Dewa atau Roh yang berkuasa untuk mempersatukan diri dengan dewa sebagai ganti hukuman manusia karna dosa. ${ }^{1}$ Bila diperhatikan dari ceritacerita kuno tentang dara cantik yang dipersembahkan kepada raksasa atau dewa untuk mencegah kehancuran suatu negeri, serta untuk membujuk dewa-dewa demi keselamatan suatu bangsa. Suku Dayak Ngaju di yakini berasal dari Pegunungan Yunan, Cina Selatan sekitar tahun 3000-1500 SM. Namun menurut cerita lain leluhur suku Dayak berasal Ranying Hatalla Langit yang ditugaskan untuk menjaga bumi dan isinya adar tidak rusak. ${ }^{2}$

Kaharingan adalah kepercayaan dari suku Dayak di Kalimantan Tengah. Kepercayaan hidup dan tumbuh secara turun temurun dan dihayati terhadap Tuhan Yang maha Esa. Dilihat dari setiap ragam upacara adat Dayak yang senantiasa menyertakan sesaji atau kurban di dalamnya. ${ }^{3}$ Hal ini pula lah yang menjadi dasar bagi suku dayak ngaju dalam melakukan setiap upacara adat disertai dengan darah hewan kurban. Dilakukan penyembelihan hewan korban yang darahnya di percikan dan di oleskan pada suatu benda yang di keramatkan bahkan juga di tubuh seseorang yang sedang melakukan upacara tersebut. Dalam upacara adat dayak ngaju pada pelaksanaannya banyak menggunakan simbol-simbol yang khas baik itu dalam bentuk verbal dan nonverbal bisanya berupa perlengkapan, benda atau barang Simbol dalam bentuk verbal berupa perumpamaan, pantun, syair, tarian, lagu dan musik dan memiliki makna yang sudah disepakati oleh damang atau ketua adat suku dayak ngaju. Simbol nonverbal berguna untuk menyampaikan makna yang disusun dalam konteks budaya dalam interaksi sosial masyarakat. Penulis melihat pada praktiknya penggunaan darah dalam upacara adat suku Dayak Ngaju lebih banyak di pakai baik itu dalam upacara pernikahan,

\footnotetext{
${ }^{1}$ M. Hashem, Misteri Darah Dan Penebusan Dosa (Jakarta: Hikmah, 2006).hal.1

2 "Suku Dayak Ngaju," Wikipedia Ensiklopedia Bebas.

${ }^{3}$ UNODC," AGAMA DAN KEBUDAYAAN KAHARINGAN DI KALIMANTAN MENURUT PARA PENULIS INDONESIA (1990-2013), 2018.
} 
upacara mamapas lewu atau menyapu kampung, upacara mapalas atau pengobatan, adapun darah hewan yang bisa di gunakan yaitu babi, kerbau, dan ayam. Suku dayak ngaju mempercayai jika darah binatang tersebut dapat menetralisir hal-hal yang buruk dan tidak baik, dan juga melambangkan hubungan antar makhluk. Salah satu upacara adat lainnya yang menggunakan darah dalam praktek ritualnya adalah tiwah, di awali dengan pembukaan balian atau orang yang di khususkan untuk bertugas memberi tahu dan meminta izin kepada roh agar tidak marah, dan menjauhkan yang jahat dari mereka yang akan melaksanakan upacara tiwah tersebut. Berikutnya mendirikan sandung namun sebelumnya mereka memercikan darah ayam atau babi pada peralatan tukang.kemudian darah tersebut di oleskan pada dahi dan leher keluaraga dan dagingnya dimasak untuk jamuan keluarga dan tamu yang datang dalam upacara tersebut. ${ }^{4}$ memiliki suatu sistem kepercayaan yang sangat kompleks dan berkembang, prinsip hal yang dijunjung tinggi oleh suku tersebut adalah unsur kepercayaan nenek moyang yang menekankan pada pemujaan nenek moyang dan kepercayaan kepada Tuhan sebagai penguasa dari kehidupan manusia. ${ }^{5}$ Namun dalam prakteknya ada beberapa kelompok yang memiliki pemahaman berbeda, ada yang menolak, ada yang tetap melakukan dengan dasar taat pada adat nenek moyang. Sulitnya mempertemukan antara ajaran kekristenan dengan budaya Dayak yang sarat akan hal mistis menimbulkan kontroversi antara kedua kubu tersebut. Penulis melihat jika hal inilah yang membuat suatu permasalah yang cukup kompleks yaitu bagaimana mempertemukan antara iman kekristenan dan kebudayaan. Teologi kontekstual merupakan salah satu hal yang menjadi usaha untuk menjelaskan persoalan yang terjadi sekaligus memberikan penjelasan yang benar tentang iman Kekristenan terkait dengan penggunaan darah dalam upacara adat tersebut.

\footnotetext{
${ }^{4}$ Andi Indah Yulianti et al., "LEKSIKON DALAM UPACARA KEMATIAN (TIWAH) SUKU DAYAK NGAJU (Lexicons in Dayak Ngaju's Death Ceremony (Tiwah) ),"Suar Bétang 13, no. 01 (2018): 65-74.

5 "Hubungan Manusia Dengan Binatang Atau Hewan," Institut Dayakologi.
} 


\section{METODE}

Metode penelitian, penulis menggunakan pendekatan metode penelitian deskriftif kualitatif, metode penelitian ini menggambarkan dan menginterpretasikan objek sesuai dengan apa adanya. Demikian juga Sugiono mengungkapkan bahwa penelitian deskriptif kualitatif adalah penelitian yang berusaha untuk menuturkan pemecahan masalah yang ada berdasar data-data mengikuti teknik pengolahan dan analisis data. ${ }^{6}$ Metode pengumpulan dengan mengkaji secara mendalam dan mempelajari latar belakang dari fenomena-fenomena yang terjadi dalam kegitan dalam upacara adat suku dayak Ngaju Kalimantan Tengah.

\section{HASIL DAN PEMBAHASAN}

\section{Sikap Teologis Terhadap Persembahan Darah}

Makna darah bagi suku Dayak Ngaju adalah zat suci, darah juga dipercayai memiliki kekuatan roh yang berasal dari Ranying Hattala Langit yang berfungsi mendinginkan dan menetralisir. Dalam upacara adat pernikahan darah digunakan saat kedua pengantin duduk di atas gong, lalu keduanya dioleskan darah babi atau ayam. Dalam Perjanjian Lama darah menunjuk kepada hidup atau maut, darah juga menunjukan kepasrahan kepada Allah. Pengertian darah dalam Bahasa Ibrani adalah "dam" dan dalam Bahasa Yunani adalah "raima" yaitu kata yang berhubungan dengan cairan hidup dalam tubuh manusia. ${ }^{7}$ Yang melekat dan memiliki kesatuan dngan jiwa sebagai mana tertulis dalam kitab Imamat 17:14 "Darah adalah nyawa segala mahluk" darah juga dapat diartikan sebagai pendamaian sebab dalam Perjanjian lama darah sering dipakai dengan arti kematian karena kekerasan dibandingan dengan arti yang lain. Dalam Imamat 17:11 arti darah dalam penetapan paskah bagi bangsa Israel adalah tanda penebusan yaitu menggantikan anak sulung mereka sebelum bangsa Israel meninggalkan mesir. Masing-masing keluarga di Israel membubuhkan darah Pada kedua tiang rumah sehingga bangsa Israel selamat ketika

\footnotetext{
${ }^{6}$ Sugiono, Memahami Penelitian Kualitatif (Bandung: CV Alfabeta, 2016).

${ }^{7}$ Ensiklopedia Alkitab Masa Kini (Jakarta: Yayasan Komunikasi Bina kasih, 1995). Hal. 236.
} 
malaikat maut melewati daerah mereka. Dalam kitab Imamat dilegalisasikan penghargaan terhadap darah yang menjadi tata hukum sehingga dalam Imamat 3:17 terdapat larangan untuk memakan darah secara turun temurun. Bahkan setiap orang yang makan darah nyawanya akan di lenyapkan. ${ }^{8}$

Ketika orang Dayak Ngaju menggunakan unsur darah dalam upacara adat yang mereka lakukan, maka secara simbolis meraka mempercayai jika benda yang dioleskan dengan darah tersebut benarbenar disucikan, selamat dari bahaya dan malapetaka, dan diberkati oleh Tuhan. Bahkan dalam upacara kehormatan atau naik pangkat serta mengangkat seorang ketua kampung akan dianggap sah ketika darah hewan tersebut dioleskan dengan jari telunjuk pada dahi orang tersebut. Unsur agama suku Dayak Ngaju yaitu hindu kaharingan sangat berperan dalam memberikan pemahaman yang kuat tentang pentingnya simbol darah dalam setiap ritual yang dilakukan karna agama ini adalah agama kehidupan dimana struktur rohani dan konfrontasi agama ini bersumber pada perasaan atau intuitif, dan mutlak berpegang pada tata tertib hidup, baik dunia dan alam. Kepercayaan ini masih melekat didalam kehidupan masytarakat suku Dayak Ngaju sekalipun ajaran kekristenan telah masuk di wilayah mereka sejak lama. Manusia dan alam merupakan suatu kesatuan yang sangat erat dalam menciptakan harmonisasi kehidupan. ${ }^{9}$ Berdasarkan pemikiran tentang pengudusan darah yang menjadi lambang korban di mezbah sebagai milik Tuhan dan darah dipandang sebagai tempat kehidupan karena nyawa makhluk ada didalam darahnya maka darah Yesus diberikan sebagai pendamaian bagi nyawa umat manusia. Dalam Perjanjian Baru, darah Yesus menandakan kuasa atas kematian dan pengorbanan-Nya di kayu salib untuk menebus dosa dan menganugrahkan keselamatan bagi umat manusia. Dalam darah-Nya ada perlindungan hal ini tertulis dalam keluaran 12:13 dimana darah menjadi tanda sehingga tulah kemusnahan tidak menimpa umatnya.

\footnotetext{
${ }^{8}$ Telhalia Telhalia, "Teologi Kontekstual Pelaksanaan Jalan Hadat Perkawinan Dayak Ngaju Di Gereja Kalimantan Evangelis (GKE)," Religió: Jurnal Studi Agamaagama 6, no. 2 (2016): 230-252. 239-240 139

${ }^{9}$ Fridolin Ukur, Tuaiannya Sungguh Banyak (Jakarta: Gunung Mulia, 2002). hal.
} 
Dalam darah ada keselamatan melalui darah Yesus yang mengalir di kayu salib sebagai korban anak domba yang tak bercela. Dalam darah ada pentahiran seperti saat imam memercikan darah tujuh kali kepada orang yang akan ditahirkan dari kusta, dan dalam darah ada pendamaian melalui kolose 1:19-22. Diperkuat dengan pernyataan Yesus dalam Markus 14:25 dimana cawan tersebut dimateraikan oleh darah-Nya untuk menyatakan ketaatan dan kehidupan serta kematianNya dalam Perjanjian Baru, yang oleh Paulus kemudian ditambahkan agar upacara tersebut seelalu diulangi untuk mengingat tentang dipersatukanya domba paskah yang telah mati disalibkan bagi kita.

Oleh sebab itu perlu adanya upaya inkultuasi dalam menyikapi berbagai tradisi turum temurun khususnya bagi suku Dayak Ngaju, sebagaimana Fredy Simanjuntak dkk menjelaskan inkulturasi memberikan pandangan tentang bagaimana bentuk-bentuk historis dari praktik-praktik Kristen diadaptasi dengan persekutuan komunitas ke dalam konteks yang muncul. ${ }^{10}$ lebih jauh lagi gereja dalam hal ini perlu pemahaman mengenai teologi kontekstual.

Teologi kontekstual merupakan suatu cabang ilmu teologi yang meneliti bagaimana ajaran Kristen dapat menjadi relevan di konteks yang berbeda-beda dan teologi ini termasuk adalah bagian dari teologi pembebasan yang merupakan sebuah paham tentang peran agama dalam ruang lingkup lingkungan sosial. Dasar dalam berkontekstualisasi adalah senantiasa berpegang pada dasar kekristenan secara historis, Allah menyatakan dirinya dalam alam ciptaan dam hati nurani. Agama-agama lain menyatakan jika manusia memiliki pengertian tentang Allah. Dalam berkontekstualisasi kekristenan harus tetap mempertimbangkan budaya asli setiap daerah hanya saja jangan menjadikan budaya tersebut berada diatas kekristenan melainkan mengungkapkan kosep-konsep Teologi yang sesuai denmgan keadaan di daerah tersebut baik itu dalam dunia roh, upacara adat, konsep kesukuan yang ada. Menjelaskan secara teliti segala istilah teologis sebagai penjaga yang perlu dalam melawan

${ }^{10}$ Fredy Simanjuntak and Yudhy Sanjaya, "Amanat Penggembalaan Dalam Ruang Virtual," Thronos 1, no. 2 (2020): 99-114. 
sinkritisme dalam kepercayaan suku tersebut. ${ }^{11}$ Makna darah dalam upacara adat suku Dayak Ngaju yang setidaknya bersentuhan langsung dengan tradisi adat Dayak tersebut. Seperti halnya makna darah bagi suku Dayak Ngaju adalah zat suci. Darah juga dipercayai memiliki kekuatan roh yang berasal dari Ranying Hattala Langit yang berfungsi mendinginkan dan menetralisir. Dalam upacara adat tolak bala darah ayam memiliki fungsi untuk persembahan bagi penjaga kampung dari serangan jin dari laut dan sebagai penangkal kesialan. Sebagian kelompok yang menolak tradisi penggunaan darah tersebut beranggapan hal tersebut bertentangan dengan iman kekristenan yang kelompok tersebut pahami. Karena iman itu berasal dari Allah dan kebudayaan berasal dari manusia. Iman yang datang dari Allah adalah murni sedangkan yang di buat oleh manusia adalah dosa. Kelompok tersebut menghakimi kebudayaan yang dinilai selalu jahat bahkan menyatakan jika orang Kristen yang masih melakukan upacara tersebut masih bersifat sinkretis yaitu Kristen magis. Semua benda yang di pakai dalam upacvara adat termasuk darah nerupakan hal yang najis dan kafir. kebalikan dari kelompok tersebut adalah memandang jika tidak adanya perbedaan antara iman dan kebudayaan mereka menjunjung tinggi kebudayaan tersebut melebihi dari iman Kristen, sehingga membuat kelompok tersebut kesulitan membedakan antara kekristenan dan budaya.

Darah merupakan lambang pertobatan, dilihat dari pemercikan darah korban dalam PL dan menjadi suatu bentuk dari penyucian seluruh umat manusia melalui kematian Kristus. Darah juga merupakan lambang pencamaran karena dosa. pencemaran karena dosa. Dalam Bahasa Ibrani darah berarti pusat kehidupan karan itu darah memiliki peran yang mendasar dalam persembahan korban dan dalam Perjanjian Lama darah dipercikan untuk menegakan perjanjian dengan Tuhan dalam keluaran 24:8 sedangkan didalam Perjanjian Baru darah Yesus menandakan kuasa kematian-Nya untuk menebus dosa. Tata upacara persembahan dengan menggunakan darah menunjukan kepasrahan hidup kepada Allah. Maut mempunyai tempat

${ }^{11}$ David J. Hesselgrave and Edward Rommen, Kontekstualisasi (Jakarta: BPK Gunung Mulia, 2004). Hal. 138. 
yang lebih rendah dan tidak mempunyai tempat sama sekali. Dan dalam pandangan ini, daeah Yesus berarti adalah hidup Yesus

Dalam PL terdapat 362 kata yang memuat tentang "dam", 203 diantaranya menunjuk kepada maut. Dan hanya 7 yang menghubungkan darah dengan hidup, serta 17 merujuk kepada makanan daging dengan darah. Dapat disimpulkan jika hubungan mautlah pikiran bila darah di sebut menurut pemahaman Alkitab. Kematian Yesus dianggap sebagai korban atau darah perjanjianakan tetapi jika di simak dengan lebih teliti kata darah perjanjian di Perjanjian Lama diartikan sebagai kematian yang mendamaikan oleh Juruselamat. Selain itu darah dapa diartikan sebagai kutuk bahkan sepuluh tulah dimulai dengan air yang menjadi darah dan ditutup dengan darah yang dibubuhkan pada tiang pintu rumah. Dalam perjanjian Lama darah digunakan untuk menyucikan dan menguduskan manusia, perabotan, dan barang-barang untuk ibadah. ${ }^{12}$

Menurut sumber lain, Tanah di suatu daerah perlu disucikan karan dalam perjalanan sejarah manusia tanah telah dikutuk oleh setan dengan mencurahkan darah ketanah yang baik oleh tanah binatang atau hewan melalui ritual adat, dan agama-agama di dunia. Kutukan tanah pertama kali adalah Ketika iblis menggerakan hati Kain untuk membunuh Habel dan mencurahkan darahnya ke tanah.

\section{KESIMPULAN}

Makna darah bagi suku Dayak Ngaju adalah zat suci, darah juga dipercayai memiliki kekuatan roh yang berasal dari Ranying Hattala Langit yang berfungsi mendinginkan dan menetralisir, menyucikan, dan lambang kepasrahan kepada Tuhan. Dalam upacara adat pernikahan darah digunakan saat kedua pengantin duduk di atas gong, lalu keduanya dioleskan darah babi atau ayam. Sedangkan di dalam konteks Perjanjian Lama darah menunjuk kepada hidup atau maut, darah juga menunjukan kepasrahan kepada Allah. Darah merupakan lambang pertobatan, dilihat dari pemercikan darah korban dalam PL dan menjadi suatu bentuk dari penyucian seluruh umat manusia melalui kematian Kristus.

12 "Studi Kamus," Alkitab Sabda. 
Hal yang penting untuk dilakukan adalah mengungkapkan kosep-konsep Teologi yang sesuai dengan keadaan di daerah tersebut baik itu dalam dunia roh, upacara adat, konsep kesukuan yang ada. Menjelaskan secara teliti segala istilah teologis sebagai penjaga yang perlu dalam melawan sinkritisme dalam kepercayaan suku tersebut. Menjelaskan jika Darah juga merupakan lambang pencamaran karena dosa. pencemaran karena dosa. Dalam Bahasa Ibrani darah berarti pusat kehidupan karena itu darah memiliki peran yang mendasar dalam persembahan korban dan dalam Perjanjian Lama darah dipercikan untuk menegakan perjanjian dengan Tuhan dalam keluaran 24:8 sedangkan didalam Perjanjian Baru darah Yesus menandakan kuasa kematian-Nya untuk menebus dosa. Tata upacara persembahan dengan menggunakan darah menunjukan kepasrahan hidup kepada Allah. Maut mempunyai tempat yang lebih rendah dan tidak mempunyai tempat sama sekali. Dan dalam pandangan ini, darah Yesus berarti adalah hidup Yesus. Kedua hal ini hamper memiliki makna yang sama.

Darah merupakan lambang pertobatan, dilihat dari pemercikan darah korban dalam PL dan menjadi suatu bentuk dari penyucian seluruh umat manusia melalui kematian Kristus. Darah juga merupakan lambang pencamaran karena dosa. pencemaran karena dosa. Dalam Bahasa Ibrani darah berarti pusat kehidupan karena darah memiliki peran yang mendasar dalam persembahan korban dan dalam Perjanjian Lama darah dipercikan untuk menegakan perjanjian dengan Tuhan dalam keluaran 24:8 sedangkan didalam Perjanjian Baru darah Yesus menandakan kuasa kematian-Nya untuk menebus dosa. Hanya Darah Yesuslah satu-satunya yang memiliki kuasa sebagai pendamaian, sebagai penyucian, dan penebusan dosa. Dasar yang benar dalam melakukan Upacara tersebut adalah mengerti dan memahami jika simbol darah yang dipakai hanyalah sebagai unsur pengingat bagi manusia bahwa manusia telah didamaikan melalui Kuasa Darah Yesus Kristus.

Sikap yang benar dalam kekristenan adalah memahami jika praktek penggunaan darah dalam upacara adat adalah sebagai simbol pembasuhan dan penyucian atau pendamaian antara manusia, alam sekitar dan Tuhan. Hal yang paling ideal adalah mengubah pandangan 
bahwa kebudayaan manusia telah dicemari oleh dosa. Serta meyakini jika Kristus telah menang atas dosa dan Roh Kudus membaharui kebudayaan dan tidak menghakimi kebudayaan tersebut. Mengubah iman menjadi nafas dalam kebudayaan lokal akan tetapi tetap bersikap kritis jika ada hal yang bertentangan contohnya penyembahan kepada berhala. Namun jika hal tersebut merupakan simbol dan tidak menjurus pada penyembahan berhala terimalah budaya tersebut sesuai dengan nafas Iman Kristen.

\section{KEPUSTAKAAN}

Hashem, M. Misteri Darah Dan Penebusan Dosa. Jakarta: Hikmah, 2006.

Hesselgrave, David J., and Edward Rommen. Kontekstualisasi. Jakarta: BPK Gunung Mulia, 2004.

Simanjuntak, Fredy, and Yudhy Sanjaya. "Amanat Penggembalaan Dalam Ruang Virtual.” Thronos 1, no. 2 (2020): 99-114.

Sugiono. Memahami Penelitian Kualitatif. Bandung: CV Alfabeta, 2016.

Telhalia, Telhalia. "Teologi Kontekstual Pelaksanaan Jalan Hadat Perkawinan Dayak Ngaju Di Gereja Kalimantan Evangelis (GKE)." Religió: Jurnal Studi Agama-agama 6, no. 2 (2016): 230-252.

Ukur, Fridolin. Tuaiannya Sungguh Banyak. Jakarta: Gunung Mulia, 2002.

UNODC. "No Titlelll!." AGAMA DAN KEBUDAYAAN KAHARINGAN DI KALIMANTAN MENURUT PARA PENULIS INDONESIA (1990-2013), 2018.

Yulianti, Andi Indah, Prodi Magister, Ilmu Linguistik, Fakultas Ilmu Budaya, Universitas Brawijaya, Jalan Veteran, Kecamatan Lowok Waru, Kota Malang, and Jawa Timur. "LEKSIKON DALAM UPACARA KEMATIAN (TIWAH) SUKU DAYAK NGAJU (Lexicons in Dayak Ngaju's Death Ceremony (Tiwah) )." Suar Bétang 13, no. 01 (2018): 65-74.

Ensiklopedia Alkitab Masa Kini. Jakarta: Yayasan Komunikasi Bina kasih, 1995.

"Hubungan Manusia Dengan Binatang Atau Hewan." Institut Dayakologi.

"Studi Kamus." Alkitab Sabda.

"Suku Dayak Ngaju." Wikipedia Ensiklopedia Bebas. 